\title{
Transfer Student Companion
}

\author{
by Thomas J. Grites and Susan Rondeau
}

Published by Houghton Mifflin Harcourt Publishing Company, 2009, 186 pages

Reviewed by

Brenda McKenzie (bmckenzi@kent.edu), Associate Director, Center for Student Involvement, Kent State University

Transfer Student Companion addresses the concept of "transfer shock" and shares ways to combat it through the completion of exercises and reflections. The authors incorporate success stories of former transfer students as well as practical advice from members of a student advisory board to assist students in a smooth transition. Although the book is designed for the initial transition period, the authors strongly encourage transfer students to continue to refer to this book as a resource during their time in college.

This book is divided into seven chapters. Chapter 1, "Making Transitions," is structured to help students focus on why they are transferring. It covers resources, terms, and other information that students need to know to successfully matriculate at their new institution. For example, authors advise transfer students to not assume that academic policies are similar at their former and current institutions and to verify that their new institution has received a final transcript from the last.

Chapter 2, "Making Primary Plans," focuses on students' academic and career plans. The exercises encourage students to determine what skills they need to develop and enhance through their course work. The authors also direct students to plan for the unexpected. One task has students setting goals in areas related to bachelor's degree, work setting/environment, lifestyle, and leisure time after graduation. Students are encouraged to choose a major quickly. What is not clearly covered is how students can balance their exploration and decision-making with institutional deadlines for major selection. A final task has students list the courses they have taken and what academic and critical thinking skills were developed from those courses. Students are encouraged to continue using this list throughout college as a way to help focus their career/job search. Providing the basis for the rest of the book, this may be the most helpful of all chapters.

Chapter 3, "Making Other Plans," addresses the need for students to develop financial, time management, engagement, and coping skills. One exercise focuses on determining expenses and cost of education and creating a plan for financing that education. The authors address their concern about the concept of "workers who happen to attend classes," suggesting that students keep work hours in mind when determining how to balance their need to work with school commitments. They also address maintaining family obligations and developing alternatives for meeting everyone's expectations. The authors provide examples of addressing this 
conflict constructively through the literature currently available to students.

Chapter 4, "Making Opportunities for My Success," examines how students define success and academic-related tasks for fulfilling that definition. Developing a relationship with an academic advisor is strongly encouraged, including identifying questions to ask at advising appointments. The authors strongly emphasize the relationship with an academic advisor as well as the use of campus resources. At times, however, their reference to an advisor may be over-selling what those professionals can do for students. Tasks within this chapter are designed to help students explore possible careers and determine how their academic courses can get them there. The authors address some typical ways in which students choose a major and include exercises to help students look beyond what they know about a major or career from just popular culture, peers, and family members.

Chapter 5, "Making My Own Success," focuses on helping students become aware of possibilities that could lead to their success. Areas of possibilities include determining if they are in the right major, balancing professors' expectations, and exploring other academic options (e.g., online courses, independent study, international study). A key message in this chapter is that students themselves are one of the best resources for ensuring their success. Exercises within this chapter help students explore their level of enjoyment and what they are learning in their major to determine if it is congruent with their lifestyle.

Chapter 6, "Making My Own Co-Curricular/Social Success," contains tasks designed to help students identify intentional co-curricular experiences that lead to success. The authors suggest that students attend certain events, become involved with specific organizations, and focus on healthy lifestyle choices. One exercise asks students to describe how events/activities they have attended contribute to their skill development.

Chapter 7, "Making the Next Transitions," focuses on the transition out of college and the job search process. The authors suggest finding a mentor, but they do not address the agreement or understanding involved in the mentor-mentee relationship. The chapter makes the process of finding an appropriate mentor sound easier than it actually is. Finally, the chapter addresses what it means to be an alumnus/a and the possible roles students could play on campus after graduation.

The book tries to appeal to multiple audiences-students who are considering transferring, those are in the process of transferring, and students who have completed the transfer process. At times, trying to address the varying needs of different groups makes the writing cumbersome. However, the authors have developed tasks and exercises that are relevant to transfer student success and that put the responsibility for success on the student. A number of tasks focus on students creating intentional academic and co-curricular experiences that will propel them to their goal of graduation.

Professionals who work with transfer orientation programs may benefit from using certain chapters or tasks from Transfer Student Companion. The best use for this workbook would be in the setting of a transfer student course because there would be accountability for completing the tasks as the self-directed learning structure requires a strong commitment from students to complete on their own. 